\title{
Visualising Actor Network for Cooperative Systems in Marine Technology
}

\author{
Yushan Pan, Sisse Finken \\ AMO, Norwegian University of Science and Technology, Ålesund, Norway \\ Dept. of Informatics, University of Oslo, Oslo, Norway \\ yushan.panentnu. no \\ IT University of Copenhagen, Copenhagen, Denmark \\ Dept. of Informatics, Linnæus University, Kalmar/Växjö, Sweden \\ sisfeitu.dk
}

\begin{abstract}
Awareness is a concept familiar to specialists within the field of Computer Supported Cooperative Work (CSCW). It is superior for analysing and describing some of the ad hoc work activities that unfold in cooperation. Such informal activities are outside the scope of engineers' formal models, which are created to tackle challenges concerning human activities and their social interactions with regards to safety concerns in operation. This paper draws on fieldwork conducted in a marine setting of offshore operations. It presents an attempt to visualise the importance of cooperative work activities that shape computer systems. The aim, thus, is to portray cooperative work in a way that can be valuable for engineers implementing marine technology. We do so by way of presenting a transferring technique (2T) using insights from the CSCW field and Actor Network Theory (ANT).
\end{abstract}

Keyword: CSCW · Awareness · ANT · Offshore operations

\section{Background}

Cooperative system design is descriptive based [1], meaning that "ethnography provides a picture of the social reality of work and interaction, one which may reveal a great deal not covered by more formal analytics procedures [2]". Cooperative systems design aims at promoting better use of technology [3] in given environments by focusing on technology, humans and social aspects of work practices. Engineers, however, find it difficult to transfer such (design) knowledge and implement it in engineering processes [4]. This increases safety challenges for offshore operations, such as ship bridge, subsea, and remotely operated underwater vehicle operations [5]. For example, as we will show in this article, marine operators want to have safety operations strengthened by using marine technology to monitor operations processes to be continually aware of on-going group activities. Yet, marine technology may not address such concerns since the primary focus of engineers is mechanical computing, with an emphasis on functionalities, rather than on social aspects, such as e.g., cooperation. We believe that automation of marine technology is their goal. CSCW designers are concerned about cooperative work and how it is supported by 
technology; however, a few studies and the existing descriptive approaches in marine context are hard understood by engineers [4]. Also, the voices of operators in the processes of systems design are omitted somehow [6].

This motivates us to explore a way of integrating both marine operators and social and material interactions into systems design for marine engineers. Awareness is a way that can further our understanding of how operators integrate their activities and abilities in a particular environment [7]. With this, CSCW designers focus on how awareness is continually established in interactions and activities an effort to complete work [8]. In response to this concern, we have created a transferring technique (2T) based on the utilisation of awareness in an actor network [9] to help both CSCW designers and engineers understand each other. $2 \mathrm{~T}$ is a technique aiming at helping CSCW designers visualise actors and their enacted actor network. Further, it should as well help CSCW designers offer a readable map to engineers enabling them to understand how to recognise and implement cooperative work when programing for cooperative systems.

\section{Challenges of Awareness and ANT in Design}

\subsection{Awareness in Design}

"Awareness is 'ongoingly' achieved in collaboration with others" in the immediate environment [8]. Individuals monitor and perceive information that is available from their colleagues and from their surrounding environment [10]. We advocate for pursuing such understanding, rather than using the original one from the ergonomics community, in which a mental model is used for acquiring information [11]. That is, awareness in CSCW focuses on how (as the case of the present study) operators acquire related activities and make sense of them, with the result that they are able to coherent their activities in relation to the activities of others. This has been identified and described in studies on the underground control [12] and in air traffic control [13].

Awareness is about observing and listening [6]. Operators display actions that may be of relevance to their colleagues with two signals: 1) I am aware of a special work that I am doing. 2) This is my activity; will you please customise your own effort accordingly to facilitate our joint work? Recently, researchers have expanded these two categorises to I-awareness and We-awareness, thereby supporting the awareness of underlying processes of shared intention, expressed through activity, which is critical for cooperation in a group [14]. This definition extends our understanding of the need to design supportive human interactions in marine technology.

We propose that awareness in marine technology is about processing known evidence. Marine operators know how to align their activities with colleagues and the artefacts on the vessel. They know how to 'perceive' their awareness and make their activities public in a material environment [15] to ensure cooperation. As Schmidt [7] states, the challenge of awareness lies in designing cooperative systems: "How do the 
actors determine what is relevant to their own efforts? How do the actors manage to sort out and pick up what is relevant? How do actors, in modulating their activities so as to make relevant aspects thereof accessible to colleagues, determine what is relevant for the others?

Even though CSCW designers are able to inform design, we must expand these questions to the activities of practical design for engineers. We believe that there should no boundary between CSCW design and engineering in the early phase of the product life cycle. If we aim to create a better marine technology, it must include the experience of operators [16]. It means that, no matter whether we are CSCW designers or engineers, it is central to outline any pre-given information processing activity in a material environment where operators' activities are relevant to their own efforts. We ask how such activities can be visualised and made apparent to the operators through the use of awareness? To our knowledge, awareness in designing cooperative systems mostly involves assumptions about acquiring information such as designing situational awareness in advanced systems [17]. Even though it is about advanced systems, cooperation between and among operators, systems, and other applicable materials, are not the main topics of such research. Awareness, as we address it, is cooperating actions and interactions in a given and meaningful environment [7].

\subsection{ANT in Design}

ANT advances a rational materiality, the material extension of semiotics, which presupposes that all entities achieve significance in relation to others. Thus, ANT highlights actors and their networks. Against this understanding, several areas of research (such as e.g., health informatics in surgery [18], the hospital environment [19], a general discussion of ANT and information systems [20]) report on design of cooperative work environments in a descriptive way. These researchers have contributed deploying ANT theoretically within CSCW.

The CSCW community has been considering how to visualise actors. Researchers have experimented with an industrial innovation aimed at helping manufacturers in France to develop the electric car market [21]. In that study, researchers highlighted specific actors in order to visualise the breakdowns in the network, and how the network functions under those conditions of breakdown, for example drivers who have to get their car to a charging terminal when they have left the car, with no power, in an area that is far away from any charging terminal [21]. Schoffelen et al. [22] suggest that there are three aspects to readability for designers when visualising an actor network: engagement, sense making, and reflection to inform design. By means of visualising things [22], actors who engage in a network can utilise their knowledge to make sense of their activities and then adjust their reactions properly to reflect the benefits of the visualisation in order to make the design more readable.

These two cases point towards how to design actor networks [23] or the interactive relations between and among actors in an actor network. Still, it is a challenge [23]. Making actors visible [21] is possible if researchers are able to draw maps [25] to give voice to the collective annotations [23] of the actors who are actively engaged in the 
work process of 'drawing things cooperatively' [22]. Storni [23] argues that "it is difficult to know if mapping the design process more explicitly and making it more public via maps would have helped the stakeholders to confront their perspectives and better inform design". We agree, yet we acknowledge that mapping the design process might be difficult. Mapping the work procedure may be less of a challenge in terms of mapping actors and their activities. A possible approach could be to customise a type of map that represents the actors in a network and their activities, which can then be used as a tool to inform design. Moreover, this would be an approach to be used when designing a cooperative system for marine technology. It is a way to depict the difference between design and engineering in marine technology; furthermore, it would lighten the approach to the relationships between the operators, the machine, and the systems from a sociotechnical standpoint in order to ensure safety operations.

\subsection{Awareness in Actor Network}

In this article, we are not using the concept of ANT as information infrastructure to understand design. Also, we are not aiming at pinpointing how ANT theoretically can help CSCW designers. ANT is more than simple conceptualizations of actors and networks. However, ANT can assist drawing relations in/of networks [24], who participates, and what type of support that is needed. This is the fundamental basis for engineers to communicate with $\mathrm{CSCW}$ designers. Hence, we aim at utilising awareness in an actor network (of marine operations) to create a common language that can serve both design work and marine engineers. To conclude this brief overview of awareness and ANT in design, we present the shared challenge of awareness and ANT: in order to visualise actors functioning in an actor network for designers and engineers, we need a concept that helps us to elaborate on what is the basis on which we visualise something [21]. What is the important thing [21] in networks and their relationships, including the actors in their network-based activities? We believe that by answering the questions we conceptually contribute to providing a mediate support between CSCW design work and engineering by borrowing the understanding of ANT to inform the design of cooperative systems through the visualisation of actors and their associated actor network.

\section{A Marine Example}

Empirical fieldwork on offshore operations at a sea-based oilfield has been conducted. Each trip on sea ranged from 7 to 14 days in the year of 2015. The first author stayed on board observing and interviewing marine operators. Permissions for fieldwork was obtained from the national research authority. In addition, informal consent forms were signed during field studies. Among several marine examples, we choose dynamic positioning (DP) operation since such marine technology is extensively used on all offshore vessels. We believe it is central for future marine research on designing for new marine and petroleum simulators. 
A DP operation is used during pre-operations to enable an offshore vessel to position itself in a proper location at sea. The DP system consists of artefacts, including the DP system, a DP checklist, and a telescope (see Fig 1). Two operators on the offshore vessel (chief and first officer) interact with the displays and operate levers that are integrated with two operational chairs in the marine operational area. The marine operational area of an offshore vessel is different when under navigation. The marine operational area is designed for offshore operations at sea.

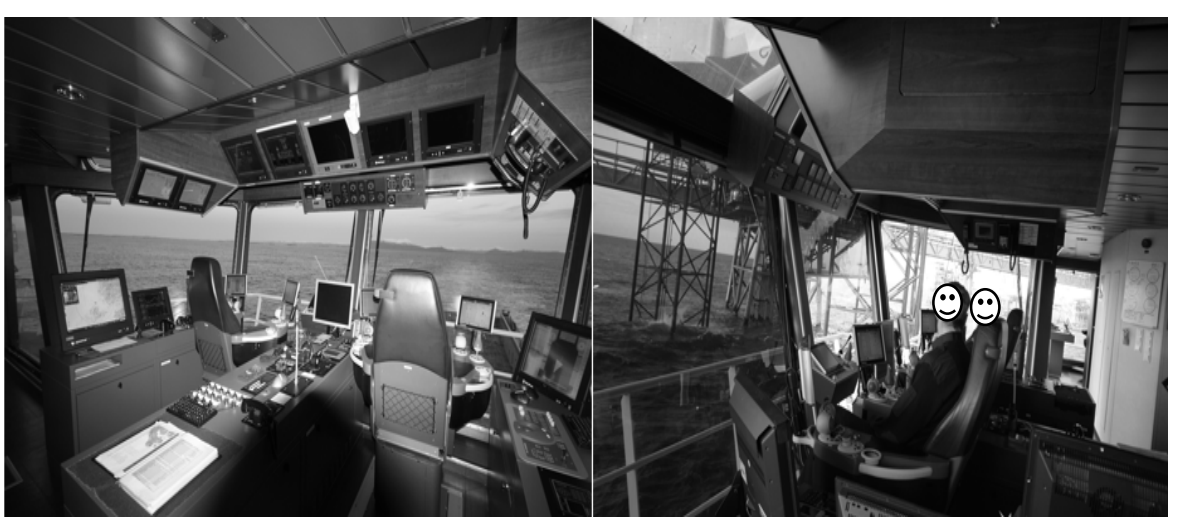

Fig1: Marine operational area on an offshore vessel.

The first officer follows the plan received from the oil company to prepare to position the vessel under platform A at ocean Norskehavet. On the vessel, he fills in the checklist (See Fig 2) for DP preparation by reading the compass to record the vessel's current position and the time. He then walks to a computer (see Fig 3), which is not a part of the marine operational area to check the weather, sea wave and wind direction from Meteorologisk, which is the Norwegian weather forecast provider. He checks the plan from the oil company against his marine journal log, and writes down necessary notes in order to remember what type of services are needed for platform A. He then completes the checklist. It is important to notice that the checklist is paperbased. Moreover, it too is not a part of the marine operational area.

The first officer does not immediately sit down to start his work. Instead, he picks up a communication device and dials a number to call the engine room. He asks the engine room about the engine status because he needs to be aware whether the vessel is in the proper condition for his operation. 


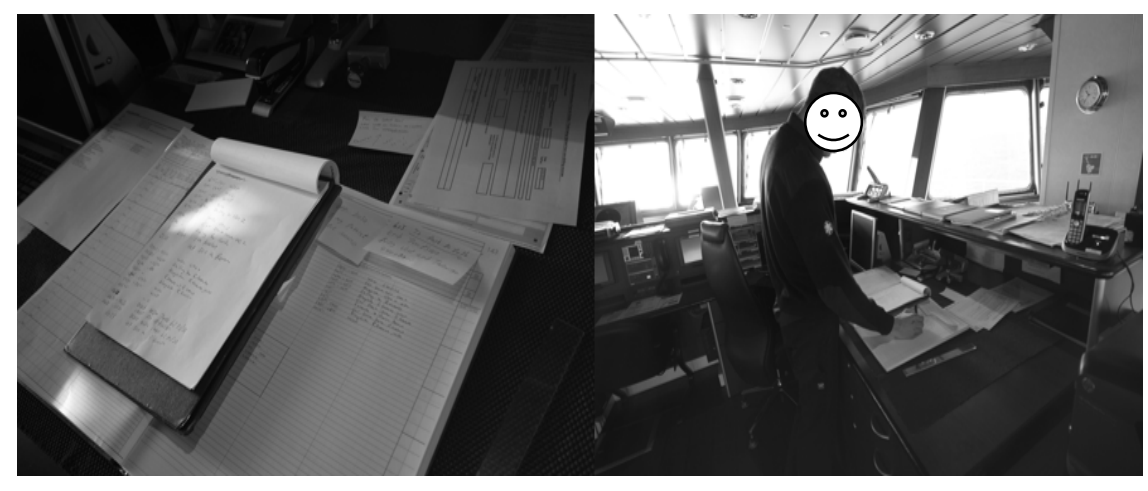

Fig 2: Checklist for DP preparation

The engine room repeats his questions and double confirms the operational conditions, including the weather conditions with both the first and chief officer. The engine room is also aware of the safety operation requirements because the DP operation must be done according to strict requirements for sea wave and wind. Then the first officer marks the engine status in the margin of the checklist and starts to position the vessel.

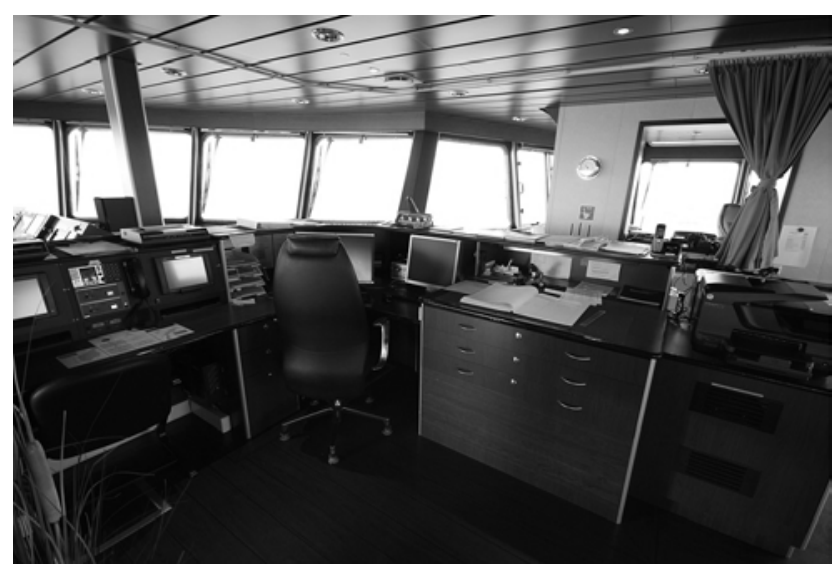

Fig 3: Computer area on the offshore vessel.

The first officer moves the vessel slowly and stops again. He passes the operation to the chief officer, picks a telescope and says: 'Could you please help me to hold my operation? I need to check where the rig is. I cannot see it because the roof of the ship's bridge is blocking my line of vision'. The chief officer stops his work checking the service plan from the oil company and holds the DP operation. The first officer walks to the window of the ship's bridge in the marine operational area and uses the telescope to look for the platform's rig (see Fig 4). He puts down the telescope and guides the chief officer orally to move the vessel gradually. Simultaneously, he talks with platform A to ensure his guidance is correct. Platform A needs to confirm that 
the vessel is in an apt position for working on the offshore operation, e.g., for loading cargo from the platform to the vessel.

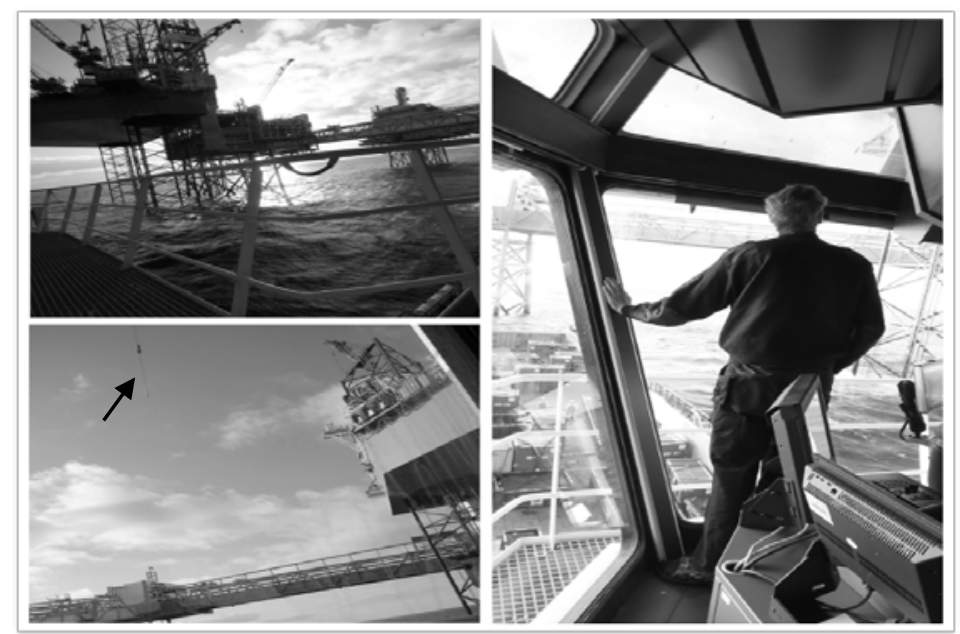

Fig 4: The first officer looks for the rig and guides the positioning of the vessel.

\section{Transferring Technique (2T)}

From the marine example, and within the optic of ANT we can see that the first officer, the computer, the checklist, the chief officer, the engine room, platform A, and the DP system are connected as actors networked to ensure the safety of the DP operation. We add the concept of awareness in the actor network to visualise these activities - 'the actors and their relationships' - in a specific DP operation at sea. The first phenomena is the self-awareness [14]: the first officer fills in the checklist but he does not need to check the engine status in relation to the process manual for DP operations. However, he is aware of the engine and that it may obstruct his work if it suddenly stops or works incorrectly, raising the possibility of unsafe events. Therefore, he calls the engine room and marks the status in the margin of the checklist. We illuminate it: I am an actor in the network and I care about information that is important to my work. I need such information to inform myself that my work is taking place under conditions of safety.

Thus, if we visualise an activity and its relationship with other activities, we must account for self-awareness of the actor doing the network. Self-awareness is the local interest of an actor who carries it out on his own and through this generates a goal for the whole actor network - here a network of safety. Hence, the current DP systems should consist of three components as a part of the function of the marine operational area: the checklist, the engine status, and the weather conditions. However, adding these functions is not about simply adding them to the current DP system. For the purpose of visualisation, we need to consider how such reshaped functions are associated with other activities in actor network. 
Since the first officer cannot check the engine status directly, he calls to the engine room for help. The engine room answers his inquiry. Additionally, he double-checks the weather conditions with both officers. It seems that the weather condition is common information for both sides - the operational area and the engine room. This can be understood as We-awareness [14]. The engine room double-checks the weather because it is also concerned about safety. The engine room needs to confirm with the officers that their operations are within those allowed under the weather conditions. Hence, the DP system changes, developing from one visualised actor to the relationships between actors who share the same interests in an actor network. Figures 5 and 6 visualise such dynamic characteristics by using case studies [26] to detail the necessary visualisations.

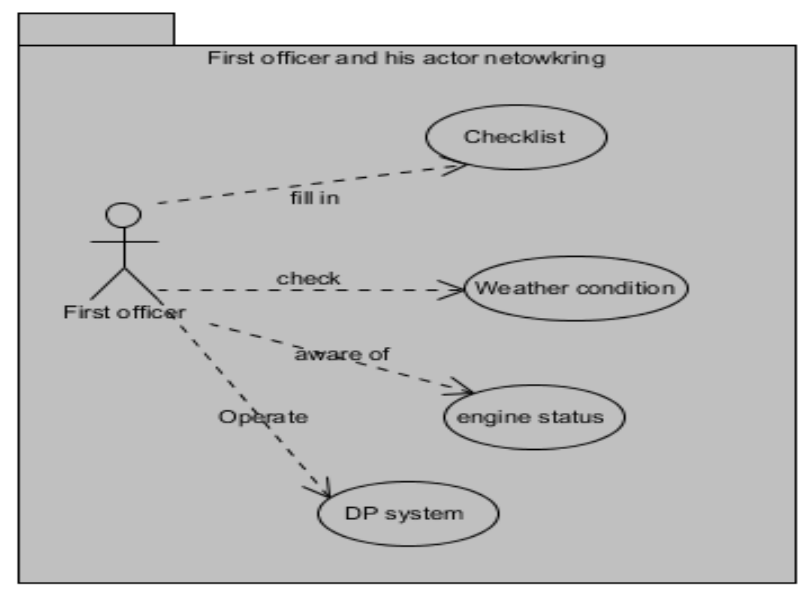

Fig 5: First officer, self-awareness and the actor network of activities

After the first officer has processed the information, he works cooperatively with the engine room; he then needs to hand over his job to the chief officer in order to find the rig to assist the vessel into its proper position. In the meanwhile, platform A also engages in the network by communicating with the chief officer. As this is happening in the actor network, each actor's interest in safety and his activities are associated with several areas of we-awareness. For example, the first officer cares whether he can successfully find the rig and helps to guide the chief officer in positioning the vessel correctly. The chief officer is aware that his ability to position the vessel depends on the oral guidance received from the first officer. Platform A needs to be aware that both officers are involved in positioning the vessel at the right point under the rig so the continuous communication between platform $\mathrm{A}$ and the first officer does not end until the vessel is in the right place. The common interest behind all these activities is safety, which is allied to the we- awareness occurring from time to time during the DP operation between the first officer and platform A, the first officer and the chief officer, the chief officer and platform A. Hence, we define allied we-awareness as group awareness. 


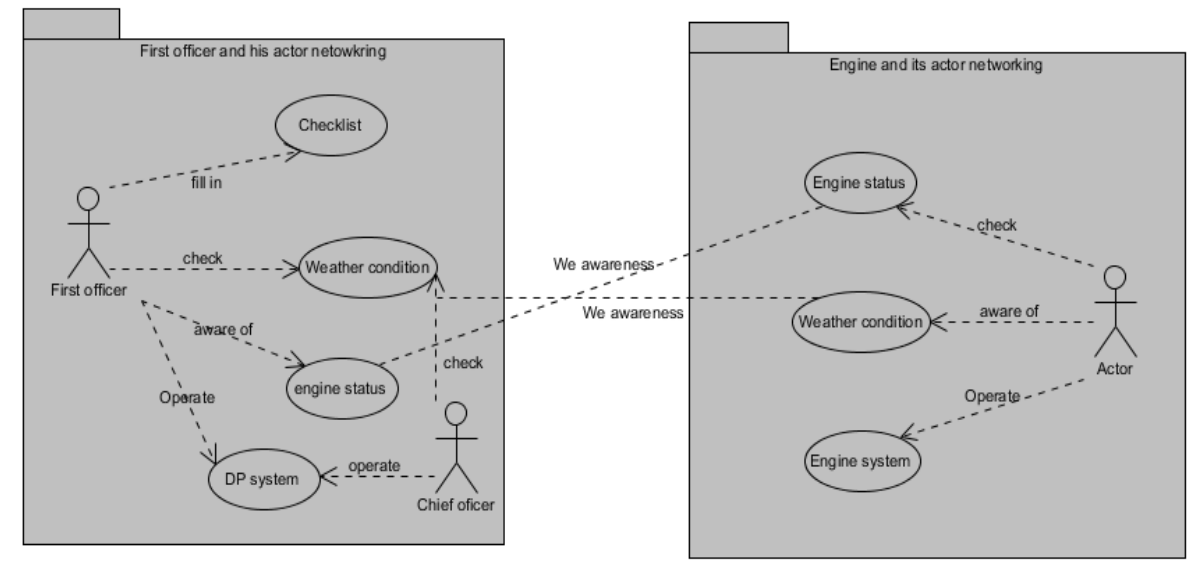

Fig 6: We-awareness, first officer, engine and their combined actor network

If we expand our understanding of such dynamic changes of alliance in weawareness, it is not difficult to describe the relationship between the DP system and the other systems on vessels. Regarding the relationship between different types of awareness, we assert that system functions based on group awareness shape the actor networks. By subscribing [23] to and from different networks of actors, the functions of marine technology are reshaped relative to the current marine systems. Through this approach, we believe actors and their interactions in actor networks can be visualised based on the systematisation of different types of awareness. Figure 7 demonstrates the visualising of interactive relations for a cooperative system. Petroski [26] states that "design is to explore everyday artefacts and sophisticated networks about the way engineers think about problems". Hence, we believe that with $2 \mathrm{~T}$ marine engineers could follow their regular practice in dividing system problems into their constituent pieces [27] and further, exercise the use of software models [28]. 2T helps to include the operators and their interactive relationships with marine technology to create an engineering approach to system development.

\section{2T-Supported Marine Technology}

2T-supported marine technology makes a twofold contribution to CSCW design for marine technology. 2T supports the design community in offering a readable visualisation [22] of actor network. With a particular emphasis on Latour's observation about making things public [29], it improves readability [22] and allows both designers and engineers to sit at the same table in understanding cooperative systems through a visualisation platform (actor network). We claim that each side of the table could make sense of the perspective made available regarding what cooperative work means. If there is no detailed explanation, the engineers will probably understand the network in terms of system requirements, as a network of the system's functionalities. Hence, it is easy for them to assemble all pieces of 
functionality as cooperative systems. Then, we assume that there is a tendency, from the engineering side, to believe that every piece of the cooperative system has a hierarchical structure. Therefore, the operators, their interactive relationships and the sense-making that evolves from their combinations are readily dismissed $[28,30]$.

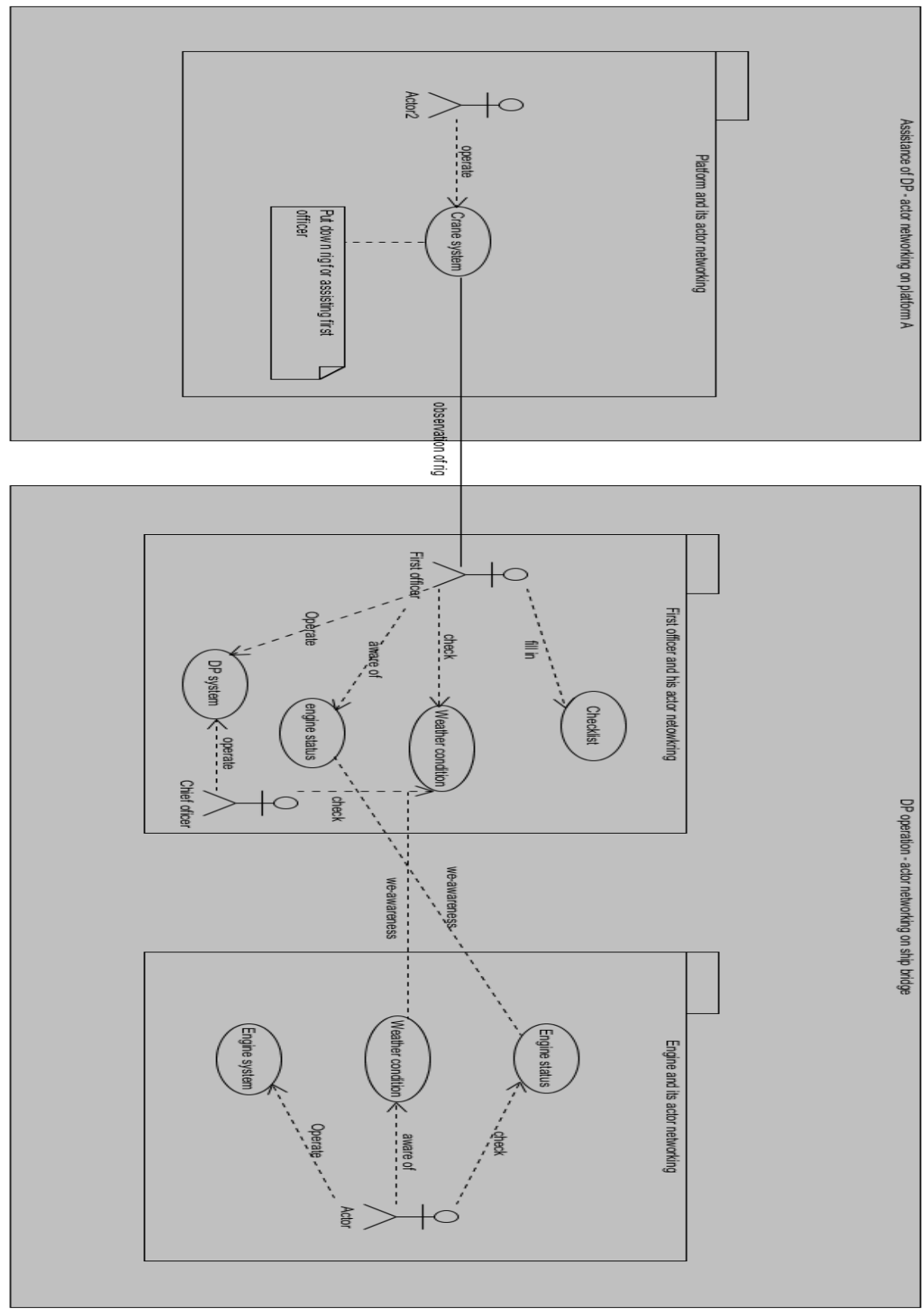

Fig 7: Actors, group-awareness and combined actor network 
On the contrary, cooperative systems conflict with such ideas in providing structure for the functions of the marine technology. Operators can tell rich stories about the operations in their living and working environment via their language, behaviour, and their reflections on their daily work. CSCW researchers engage in situated environments to learn from operators. Furthermore, such understanding from designers must be delivered to engineers. 2T provides CSCW designers possibilities to do so by integrating social activities that outside the functionalities of marine technology. Additionally, $2 \mathrm{~T}$ enlightens engineers a way to re-engineering functions of marine systems to support cooperative work. Such way contributes in helping engineers to understand that the work procedures of the operators are shaped and reshaped based on a given material environment-the marine operational area. Moreover, such way contributes to highlight actors in actor network with specific supported functions for different offshore operations. In this way, engineers could understand operators regulate their activities by combining both material and places with regard to their common interest in actor network-the safety operation through the existing diagramming techniques, i.e., UML. To some extent, such activities enforce the safety attributes of the offshore operations, and of course challenging the structure of current DP systems. For cooperative systems, to consider the complexity of the system from a single perspective only is not enough. Noticeably, the nonfunctionality of cooperative systems, such as human operators and their influence on the work in a particular setting, may result in a great impact on the system's structure.

Sørgaard [31] suggests that cooperative work is non-hierarchical; that is, cooperation "is to work or act together for a shared purpose. The work is done in an informal, normally flat organisation". We acknowledge this reference and reflect on the visualisation of actors. From time to time, actors engage in actor networks with an awareness of their own role in shaping and reshaping work procedures and therefore the ability to cause dynamic changes in the network. Network happens in a flat organisation. It is not only about the systems' ability to help the operators to complete their marine tasks, but it also identifies who is in the network, doing what, with whom, using which part of the system, and to what purpose. In this case, the operator is aware of his own work and conducts his activity publically [8]. Awareness in actor network frames the relationships between and among the network as self-, we- and group- awareness. This phenomenon enables us to understand cooperative systems from the designers' perspective, and what the system development may need to improve. It is not a way of moving simply from requirement to programming and engineering design. Instead, $2 \mathrm{~T}$ is a technique by which designers can validate requirements by logically following the visualised actors and their associated network. Hence, the functionalities in cooperative systems are organised to assist the visualised network rather than as standalones to realise the basic functions.

$2 \mathrm{~T}$ allows designers to communicate with engineers via a visualisation method. $2 \mathrm{~T}$ permits designers to explain and visualise network to engineers. In marine technology, safety is an important factor in every kind of product and usage [16]. 2T is developed based on awareness in actor network. All types of awareness are geared towards safety as the goal. We believe $2 \mathrm{~T}$ could serve as a technique for enhancing marine technology by engaging design knowledge in the engineering field. Storni [23] 
suggests that visualising the network could provide a method for design that allows the actors themselves to indicate their concerns. For marine engineers, the actors' concerns are represented as system requirements. Thus, a common understanding between the designers and engineers is essential.

Also, it should be noted that $2 \mathrm{~T}$ does not deny mechanical computing with an emphasis on functionalities. $2 \mathrm{~T}$ could serve as an alternative that takes into accounts operators' actual work situation. In its present form, mechanical computing has little potential for take care of the human factors [32], including an inability to understand the influence of cooperative work and its supporting systems in real life. 2T offers an opportunity to bridge the distance between design and engineering by allowing design knowledge to support engineers in realising the functions of cooperative systems. By following the actor network provided by CSCW designers, engineers can detail and realise functions that will support each of the actors and their interactive relationships. We believe this could provide the operator with a better experience when using the marine operational area and feeling safe in their daily activities.

\section{Concluding Remarks}

Safety concerns in offshore operations are essential. We have used awareness and ANT to visualise an actor network on an offshore vessel in an effort to capture activities and their social interactions in a material environment (involving humans, marine technologies, and material employed by humans) to help dealing with such safety concerns in system development. By doing so, we illuminate $2 \mathrm{~T}$ for engineers designing marine technology by visualising the importance of cooperative work activities that shape computer systems on an offshore vessel. It is our aim that $2 \mathrm{~T}$ can assist in enhancing mechanical computing by including socio- and material activities, rather than leaving them out in formal models. In this way, we aim at supporting engineers to implement cooperative system to scope operators' activities and their social interactions.

Acknowledgements. This research is funded by the research council of Norway via Norwegian University of Science and Technology in Ålesund. Special thanks to maritime simulation developers in NTNU Ålesund for interesting discussion on development of cooperating systems.

\section{References}

1. Crabtree, A.: Designing Collaborative Systems: A Practical Guide to Ethnography. Springer-Verlag London, London (2003)

2. Randall, D. and Rouncefield M.: Fieldwork for Design: Theory and Practice. Springer-Verlag London, London (2007)

3. Ciborra, C.: The Labyrinths of Information: Challenging the Wisdom of Systems. Oxford University Press, Oxford (2002) 
4. Baxter, G., Sommerville, I.: Socio-technical systems: From design methods to systems engineering. Interacting with Computers. 23(1) 4-17 (2011)

5. Vederhus, L., Pan, Y.: Surface-to-seabed Safety: Advantages of Simulator Practice for Subsea Installation. International Journal of Safety and Security Engineering. 0(0) 1-9 (2016)

6. Homlong, E., et al.: Simulation-based Learning: Comparative Review between Maritime Simulation and Other Domains. 13th International Conference on Probabilitics Safety Assessment and Management. Seoul (2016)

7. Schmidt, K.: The Problem with 'Awareness': Introductory Remarks on 'Awareness in CSCW'. Computer Supported Cooperative Work. 11(3) 285-298 (2002)

8. Heath, C., et al:: Configuring Awareness. Computer Supported Cooperative Work. 11(3) 317-347 (2002)

9. Law, J.: After ANT: complexity, naming and topology. The Sociological Review. 47(S1) 1-14 (1999)

10. Gutwin, C., Greenberg, S.: A Descriptive Framework of Workspace Awareness for Real-Time Groupware. Computer Supported Cooperative Work. 11(3) 411446 (2001)

11. Endsley, M.R.: Toward a Theory of Situation Awareness in Dynamic Systems. Human Factors: Journal of the Human Factors and Ergonomics Society. 37(1) 32-64 (1995)

12. Heath, C., Luff, P.: Collaboration and control: Crisis management and multimedia technology in London Underground Line Control Rooms. Computer Supported Cooperative Work. 1(1) 69-94 (1992)

13. Hughes, J.A., Randall, D., Shapiro, D.: From ethnographic record to system design. Computer Supported Cooperative Work. 1(3) 123-141 (1993)

14. Tenenberg, J., Roth, W.-M., Socha, D.: From I-Awareness to We-Awareness in CSCW. Computer Supported Cooperative Work 1-44 (2015)

15. Robertson, T.: The Public Availability of Actions and Artefacts. Computer Supported Cooperative Work. 11(3) 299-316 (2002)

16. Bjørneseth, F.B., Dunlop, M.D., Hornecker, E.: Assessing the effectiveness of direct gesture interaction for a safety critical maritime application. International Journal of Human-Computer Studies. 70(10) 729-745 (2012)

17. Endsley, M.R.: Designing for Situation Awareness: An Approach to UserCentered Design. CRC, London (2011)

18. Aanestad, M.: The Camera as an Actor Design-in-Use of Telemedicine Infrastructure in Surgery. Computer Supported Cooperative Work. 12(1) 1-20 (2003)

19. Berg, M.: On Distribution, Drift and the Electronic Medical Record, in Proceedings of the Fifth European Conference on Computer Supported Cooperative Work. pp. 141-156. Springer Netherlands, Dordrecht (1997)

20. Hanseth, O., Aanestad, M., Berg, M.: Guest editors' introduction: Actor-network theory and information systems. What's so special? Information Technology \& People. 17(2) 116-123 (2004)

21. Laurent, B., Tironi, M.: A field test and its displacements. Accounting for an experimental mode of industrial innovation. CoDesign. 11(3-4) 208-221 (2015) 
22. Schoffelen, J., et al.: Visualising things. Perspectives on how to make things public through visualisation. CoDesign. 11(3-4) 179-192 (2015)

23. Storni, C.: Notes on ANT for designers: ontological, methodological and epistemological turn in collaborative design. CoDesign.11(3-4) 166-178 (2015)

24. Law, J.: On recalling ANT. Actor Network Theory and After. The Sociological Review. 47(S1) 15-25 (1999)

25. Venturini, T., et al.: Designing Controversies and Their Publics. Design Issues. 31(3)74-87 (2015)

26. Petroski, H.: Invention by Design -How Engineers Get From Throught to Thing. Harvard University (1996)

27. Pahl, G., et al.: Engineering Design A Systematic Approach. Springer-Verlag London, London (2007)

28. Sommerville, I.: Software Engineering. Pearson Addison Wesley, London (2007)

29. Latour, B.: From Realpolitik to Dingpolitik - An Introduction to Making Things Public application. pp. 14-43 (2005)

30. Hachani, S., Gzara, L., Verjus, H.: A service-oriented approach for flexible process support within enterprises: application on PLM systems. Enterprise Information Systems. 7(1) 79-99 (2013)

31. Sørgaard, P.: A cooperative work perspective on use and development of computer artifacts, Proceedings of IRIS 10. pp. 1-23. Scandinavian Chapter of the Association for Information Systems, Tampere, Finland (1987)

32. Eder, W.E.: Engineering Design vs. Artistic Design: Some Educational Consequences. US-China Eucation Review A. 3(4) 259-280 (2013) 